\title{
REFERENCE STATIONS FOR CHRISTCHURCH
}

\author{
C. Van Houtte ${ }^{1}$, O.-J. Ktenidou ${ }^{2}$, T. Larkin ${ }^{3}$ and A. Kaiser ${ }^{4}$
}

\begin{abstract}
SUMMARY
During the Canterbury earthquake sequence, the observed level of ground motion on the soft soils of Christchurch was very strong and highly variable. Many studies are now emerging that analyse the amplification effect of these soft soils, usually by estimating a frequency-dependent amplification function relative to a rock outcrop station, or 'reference site'. If the rock outcrop has its own amplification due to weathering or topographic effects, then the calculated amplification for the soil sites can be compromised. This study examines ten seismic stations in Canterbury to determine the best reference site for Christchurch, using the horizontal-to-vertical spectral ratio (HVSR) method for S-wave shaking. More broadly, this study uses HVSR to expand existing knowledge of the dynamic characteristics of seismic stations in the Canterbury area. Most rock stations show their own local amplification effects that reduce their individual ability to be used as reference stations. The recently installed Huntsbury station (HUNS) appears to be the best reference site for Christchurch, but this will need to be verified when more records become available. In the meantime, the D13C temporary station is currently the best reference station for site effect studies in both Christchurch and Lyttelton.
\end{abstract}

\section{INTRODUCTION}

The Canterbury earthquake sequence that began in September 2010 with the $M_{w} 7.1$ Darfield earthquake has resulted in a large amount of seismic data being collected and made publicly available. Researchers locally and around the world are able to download data from the GeoNet website [1] and analyse the data using the available information. While information on the instrument is readily available, little is known about the local site conditions at each station. The site classifications given for each station are usually estimated from geological maps, and give a basic indication of the surface geology. However, little or no other site information is available, which make any rigorous analyses of the available data challenging.

One of the primary observations from the earthquake sequence is the strong and spatially variable site effects. It is therefore of engineering and seismological interest to quantify the site amplification effects in the Christchurch area for future sitespecific investigations and microzonation studies. Site effects are usually quantified relative to the bedrock beneath the site, and it is commonly assumed that a rock outcrop is a reasonable representative of the ground motion at the bedrock beneath a site.

A popular method to quantify site effects in the vicinity of seismic stations is known is the standard spectral ratio method (SSR). This method calculates the frequency-dependent amplification at a site relative to an outcropping rock, or reference station [2]. The Fourier amplitude spectrum (FAS) of a ground motion recording can be represented as a

\footnotetext{
${ }^{1}$ PhD Candidate, Department of Civil Engineering, University of Auckland

${ }^{2}$ Post-doc Researcher, Institut des Sciences de la Terre, Grenoble, France

${ }^{3}$ Senior Lecturer, Department of Civil Engineering, University of Auckland

${ }^{4}$ Researcher, GNS Science, Lower Hutt
}

multiplication of the source, path, site effect and instrument response as follows:

$$
A_{i j}(f)=S_{i}(f) \cdot P_{i j}(f) \cdot G_{j}(f) \cdot I_{j}(f)
$$

where $A_{i j}(f)$ is the FAS of event $i$ recorded at station $j, S_{i}(f)$ is the source term of event $i, P_{i j}(f)$ is the path term between source $i$ and the station $j, G_{j}(f)$ is the site response of station $j$ due to local surface geology and $I_{j}(f)$ is the instrument response of the station $j$. The SSR is obtained by dividing the FAS from station $j$ by that of a nearby reference station $k$ for the same event:

$$
\frac{A_{i j}(f)}{A_{i k}(f)}=\frac{S_{i}(f) \cdot P_{i j}(f) \cdot G_{j}(f) \cdot I_{j}(f)}{S_{i}(f) \cdot P_{i k}(f) \cdot G_{k}(f) \cdot I_{k}(f)} .
$$

If a common event (or events) with a similar source-to-site wave path is used (and instrument response is corrected), the difference between the two spectra can mainly be attributed to surface geology, and equation (2) can be reduced to the following:

$$
\frac{A_{i j}(f)}{A_{i k}(f)}=\frac{G_{j}(f)}{G_{k}(f)},
$$

known as the SSR. For $A_{i j} / A_{i k}$ to represent the site amplification, the reference station is assumed to be located on a half-space and have a flat site response i.e. theoretically $G_{k}(f)=1$ at all frequencies [3]. A reference station that 
exhibits this property is often difficult to find in practice. Weathering of rock and 2D/3D effects can result in some rock sites showing their own site response $[4,5]$. However, the assumption of flat response, if not unity, is critical as any local amplification peak or deamplification trough at reference site $k$ will result in the calculated amplification at the station $j$ being under-estimated or over-estimated respectively. Cadet $e t$ al. (2010) [6] define a standard rock site (i.e. reference station) as "a site with $V_{\mathrm{S} 30}$ between 750 and $850 \mathrm{~m} / \mathrm{s}$ and a fundamental frequency, $f_{0}$, higher than $8 \mathrm{~Hz}$ ", the criteria that will be used in this study.

Opinions are divided regarding the best site to use as a reference for Christchurch. Smyrou et al. (2011) [7] use the Lyttelton Port Company strong motion sensor (LPCC) as the bedrock motion to perform a $1 \mathrm{D}$ ground response analysis for a generic soil profile in Christchurch. Guidotti et al. (2011) [8] use LPCC to calculate SSRs for four soft sediment sites located in the $\mathrm{CBD}$, using just one earthquake record. Bradley and Cubrinovski (2011) [9] assume that LPCC exhibits the characteristics of an engineering bedrock site, and compare the LPCC response spectrum from the $M_{w} 6.3$ February 2011 Christchurch earthquake to that of a nearby station on stiff soil. On the other hand, Kaiser et al. (2011) [10] use the Canterbury Ring Laser (CRLZ) National Network station as the reference for SSRs on a dense array of sensors distributed in the Christchurch CBD, while Taber and Cowan (1993) [11] and Toshinawa et al. (1997) [12] used a temporary sensor, placed in the same facility where the CRLZ sensor is currently located, to examine SSRs in central Christchurch. While the choice of reference station may depend on the objective of the particular study, the lack of consensus and justification for the choice is the motivation for this study.

With little geological or geotechnical information at the rock stations in the Canterbury region, the purpose of this study is to determine the best reference station by calculating the site response of ten stations using a non-reference method. Further, the study intends to give additional site information on these rock stations to supplement the current knowledge of site response and its variability.

\section{HORIZONTAL TO VERTICAL SPECTRAL RATIOS}

Horizontal-to-vertical spectral ratios (HVSRs) are used in engineering seismology to estimate the frequency-dependent site amplification at a site, without specifying a reference station. Originally proposed by Nakamura (1989) [13] for microtremors, the method was extended to apply for S-wave shaking by Lermo and Chávez-García (1993) [14]. The Swave HVSR technique has been used extensively in practice and has been shown to yield a similar fundamental frequency and shape of amplification function to the SSR reference station method described above, while slightly underestimating the exact levels of amplification [15]. Although this method is considered to provide good estimates of the fundamental frequency of the site, it does not always successfully identify any subsequent peaks at higher frequencies. It can be applied to amplification from both soft soil deposits and topographic effects [16].

To obtain HVSR curves for a station, several earthquake recordings are selected, with Fourier spectra obtained using a Fast Fourier Transform (FFT). Then, all the events for a horizontal component are divided by their corresponding vertical components. These $\mathrm{H} / \mathrm{V}$ curves are averaged for all the events to give the final HVSR (usually greater than 10 events gives a reliable average). The calculated average is based on the assumption that the distribution of HVSR is normal on a log scale and not a linear scale, as investigated and validated by Ktenidou et al. (2011) [17].
The underlying assumption of this method is that the vertical component is unaffected by surface amplification, within about a factor of two $[14,18]$. This means that any rock site effects that amplify or deamplify the ground motions by a factor of two or more will be discernible on the HVSR curve.

\section{DATA}

This study analyses ten stations that are located at either Class A/B (rock) or C (stiff soil) sites [19] in the vicinity of Christchurch. The following stations were pre-existing before the $M_{w} 6.3$ February 2011 Christchurch earthquake (numbers correspond to the station locations shown in Figure 1):

1. Canterbury Ring Laser (CRLZ); and

2. Lyttelton Port Company (LPCC).

Other rock stations that have been installed since the Christchurch earthquake include:

3. Godley Drive (GODS);

4. Sign of the Kiwi (initially temporary station D13C, now STKS);

5. Kennedy Bush Reserve (temporary station D14C);

6. Mount Pleasant Drive (initially temporary station D15C, now MTPS); and

7. Huntsbury (HUNS).

With many near-source records, it is critical for a reference station to be located close to the Christchurch CBD, to minimise differences in near-source and path effects. These seven stations, located in the Port Hills within $15 \mathrm{~km}$ of the $\mathrm{CBD}$, are therefore the only stations that are considered to qualify to be a reference site for estimation of site amplification in Christchurch.

To further supplement the current knowledge of site effects, three additional stations are assessed using HVSRs: the Heathcote Valley School station (HVSC, station 8 in Figure 1); the McQueen's Valley station (MQZ, not pictured, located 20km south of Christchurch); and the Oxford station (OXZ, not pictured, located $45 \mathrm{~km}$ northwest of Christchurch). However, none of these are considered to make a good reference station as HVSC is a stiff soil site, while MQZ and OXZ are too far from Christchurch for SSR techniques.

Of the ten stations, CRLZ, MQZ and OXZ belong to the New Zealand National Seismograph Network, comprising both strong motion and broadband sensors, while the other stations are strong motion sensors. The sampling frequency of all the stations is $200 \mathrm{~Hz}$, except for MQZ and OXZ, for which the acceleration channels sample at $50 \mathrm{~Hz}$.

A dataset was compiled of 446 events recorded by at least one of the ten stations, resulting in 1,566 three-component recordings. The majority of these records had epicentral distances within $200 \mathrm{~km}$. Recordings were baseline-corrected, then time windows for S-wave shaking and pre-event noise were selected. Signal windows were selected to encapsulate the main portion of $\mathrm{S}$-wave shaking, with the minimum window length being four seconds to ensure a minimum spectral resolution of $0.2 \mathrm{~Hz}$. Noise windows were selected either from pre-event noise, or if this was unavailable, the last part of the trace to minimise any wave reflections in the noise window. Both signal and noise windows were cosine-tapered $(5 \%)$ and Fourier transformed. We chose to discard records with a signal-to-noise ratio (SNR) of less than three in the 1$20 \mathrm{~Hz}$ frequency range $(1-15 \mathrm{~Hz}$ for recordings at LPCC, which is a particularly noisy station) or those which did not pass a visual quality check, leaving a refined dataset of 325 events and 1,115 recordings. Figure 2 shows the epicentre locations of the subset of events, while Table 2 details the site 


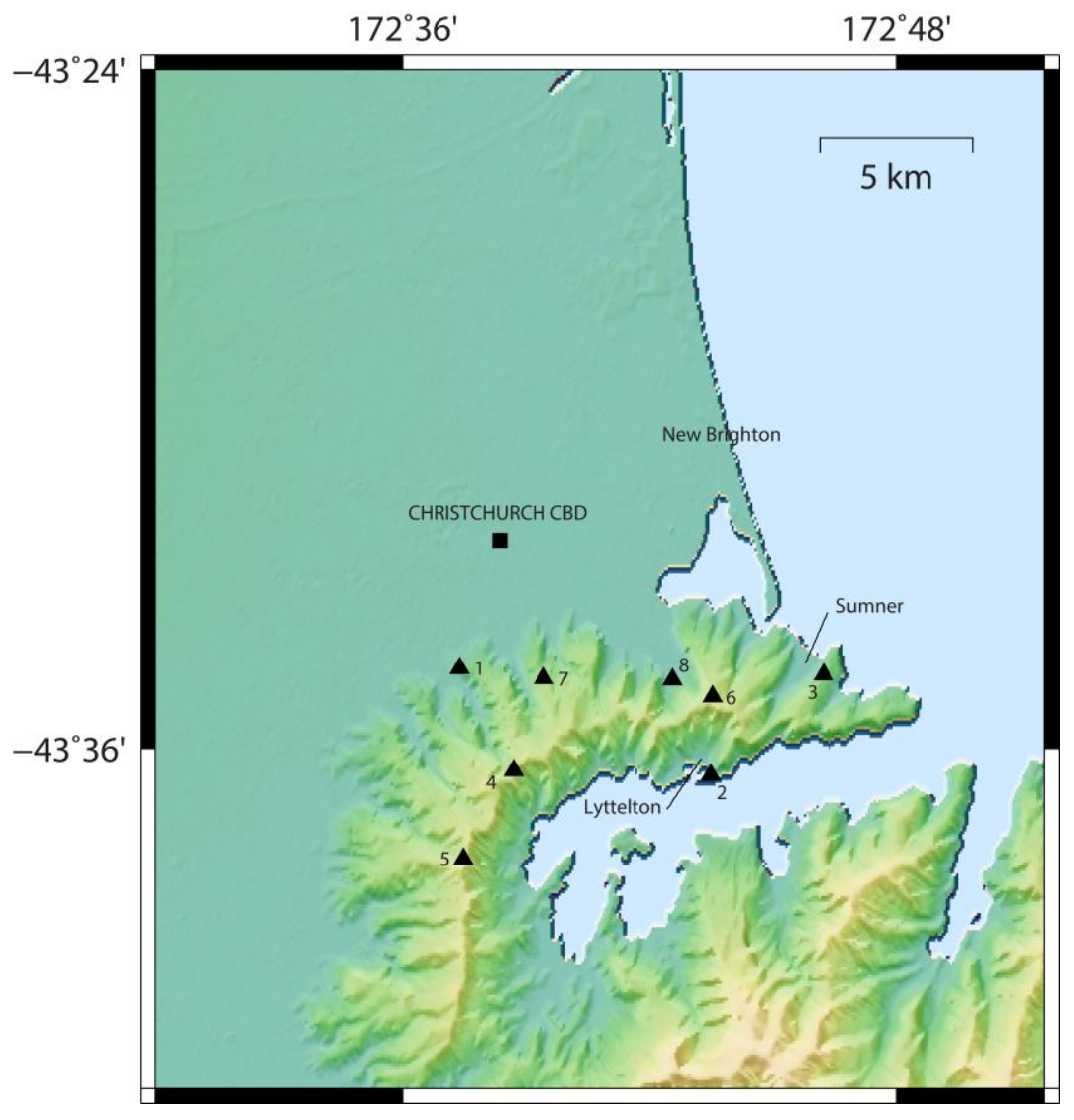

Figure 1: Station locations relative to Christchurch CBD. Numbers correspond to the station name described in the text and black area represents the volcanic rock outcrop of the Port Hills.

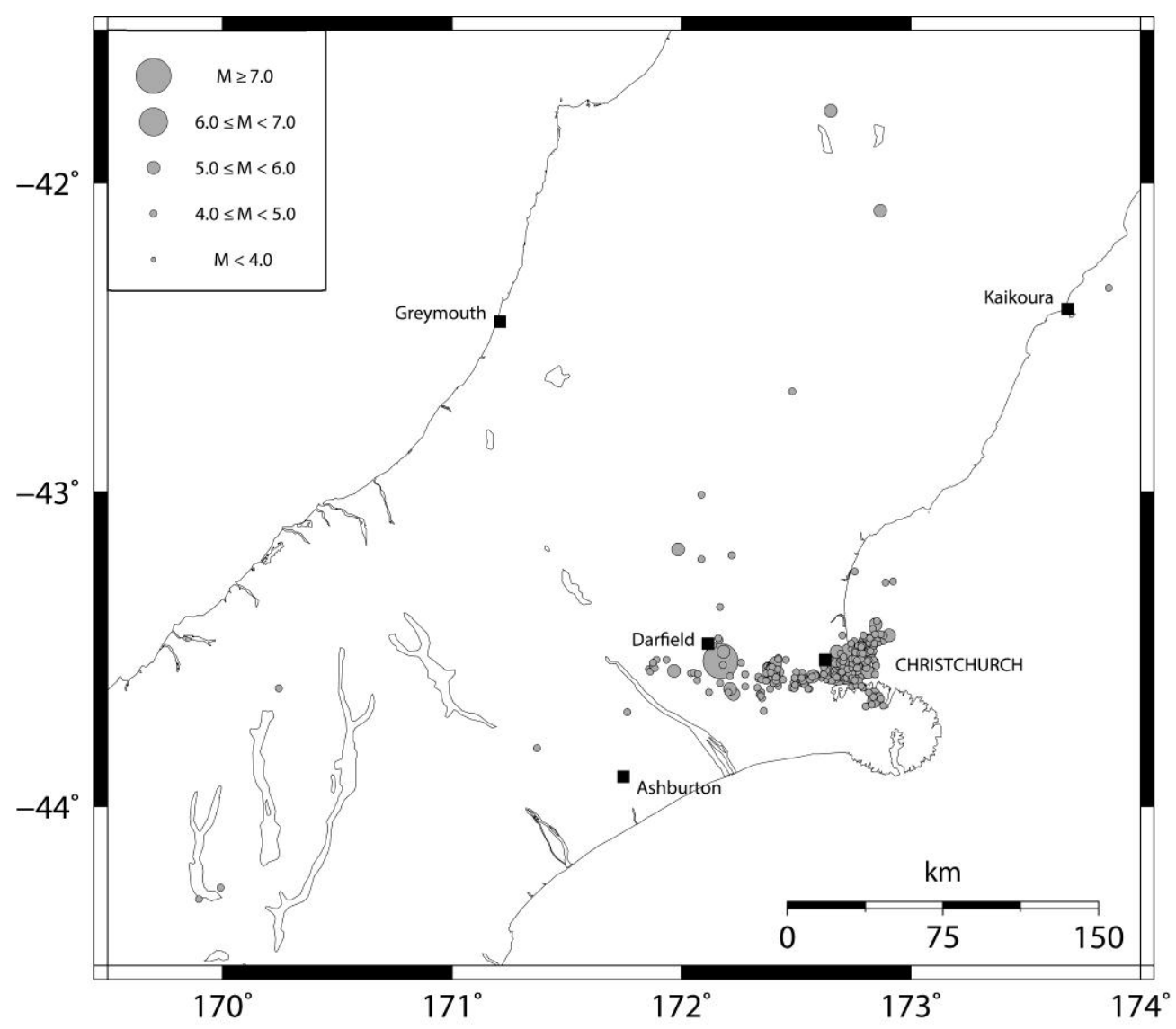

Figure 2: Epicentres of the events that form the dataset used in this study. 


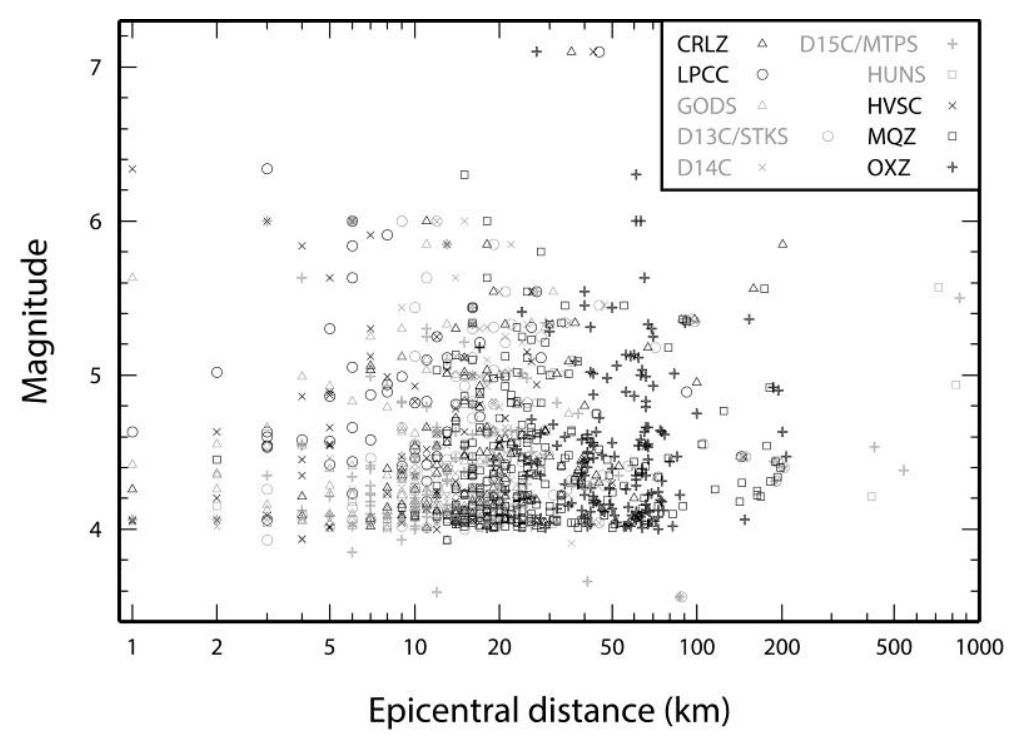

Figure 3: Magnitude-distance distribution of events. All magnitudes are local magnitudes $\left(M_{L}\right)$, except for the four largest events being moment magnitudes $\left(M_{w}\right)$. Black symbols represent stations installed before 22/02/11, grey symbols represent stations installed after 22/02/2011.

Table 1: Summary of dataset

\begin{tabular}{cccc} 
Station & $\begin{array}{c}\text { NZS1170.5 } \\
\text { Site } \\
\text { Class }\end{array}$ & $\begin{array}{c}\text { Initial } \\
\text { number of } \\
\text { recordings }\end{array}$ & $\begin{array}{c}\text { Retained } \\
\text { recordings }\end{array}$ \\
\hline CRLZ & B & 161 & 145 \\
LPCC & B & 182 & 54 \\
GODS & $B^{*}$ & 108 & 103 \\
D13C / STKS & B $^{*}$ & $78 / 63$ & $68 / 55$ \\
D14C & $B^{*}$ & 121 & 104 \\
D15C / MTPS & B* & $111 / 23$ & $95 / 23$ \\
HUNS & $B^{*}$ & 12 & 9 \\
HVSC & C & 198 & 64 \\
MQZ & B & 256 & 230 \\
OXZ & B & 253 & 165 \\
\hline Total & - & $\mathbf{1 , 5 6 6}$ & $\mathbf{1 , 1 1 5}$ \\
\hline
\end{tabular}

* not specified by GeoNet, estimated from geological maps

classifications and numbers of events recorded at each station. An asterisk denotes site classifications that are not specified on the GeoNet website, but have been deduced from geological maps [20].

Figure 3 shows the magnitude-distance distribution of events for the selected stations. Epicentral distances of greater than $200 \mathrm{~km}$ were only retained for the MTPS and HUNS stations, to ensure that there were sufficient events to get a reliable average for the HVSR. Note that with many near-source recordings (total of $799<30 \mathrm{~km}$ ), it is likely that some of the recordings will have oblique incident wave arrivals, which may give a different spectral ratio to far-field events where wave arrivals are likely to be vertically propagating. However, with a large number of events coming from a wide range of azimuths, we assume that the average HVSR curve will be unaffected, with oblique arrivals only affecting the variance of the results. HVSRs for the above dataset were calculated by obtaining Fourier spectra using the FFT, smoothing twice with a Hanning window before dividing the horizontal component by the vertical component.

\section{RESULTS}

\section{Canterbury Ring Laser (CRLZ)}

The CRLZ National Network station has been used by Kaiser et al. (2011) as the reference station for Chrischurch CBD, and a similar site was used by Taber and Cowan (1993) and Toshikawa et al. (1997). According to the GeoNet website [1], CRLZ is located on basalt rock, located in a cavern near the base of a broad ridge. The cavern is approximately 30 metres below ground surface [21]. The station malfunctioned during the Christchurch earthquake and again during the 13 June 2011 event, however there are still 145 recordings that form the average HVSR, shown in Figure 4.

A difference between the two horizontal components is evident, at its greatest between 1.5 and $4 \mathrm{~Hz}$, while still being within one standard deviation. There also appears to be an amplification peak at $1 \mathrm{~Hz}$ and a sharp trough at $7 \mathrm{~Hz}$. The 1 $\mathrm{Hz}$ peak on the NS component is likely due to topographic effects, as the amplification is only on one component and the peak is at a low frequency. However the effect is mild as the majority of the difference is within a factor of two of unity.

Conclusions regarding the cavern effects are more difficult. The tunnel is 10 metres wide and 7 metres high, which is likely to be large enough to cause scattering of seismic waves and therefore increase the variability of the CRLZ station response. However, the sharp peaks and troughs can be

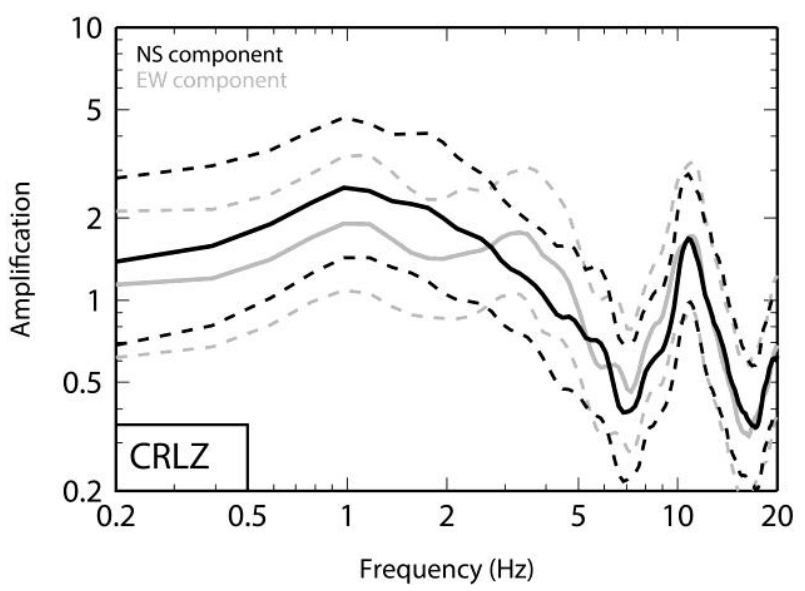

Figure 4: HVSR amplification function for CRLZ northsouth (black) and east-west (grey) components. Dashed lines represent +/- one standard deviation from the mean (solid line). 
interpreted to be due to interference (both constructive and destructive) between the incident waves and the down-going waves reflected from the free-surface. It is likely that the peaks and troughs in the higher frequency range $(\geq 7 \mathrm{~Hz})$ are due to these effects, and as such there may be real deamplification of the horizontal ground motion at 7 and 17 $\mathrm{Hz}$.

In any case, using CRLZ as a reference (i.e. assuming flat response) will result in underestimation and overestimation of the actual amplification at the target site at $0.5-2 \mathrm{~Hz}$ and $6-8$ $\mathrm{Hz}$, respectively. Although we have no information on $\mathrm{V}_{\mathrm{S} 30}$, CRLZ does not technically comply with the criteria set out by Cadet et al. (2010) as it has a fundamental frequency less than $8 \mathrm{~Hz}$.

\section{Lyttelton Port Company (LPCC)}

The Lyttelton Port Company station (LPCC) is located on the ground floor of a two-storey structure at the eastern end of Lyttelton Port. The toe of a steep cliff is located 60 metres north-east of the building, with the inside edge of the port structure about 80 metres to the west. Access to the site is restricted, as it is located on private land. Little is known about the surface geology beneath the station. GeoNet reports a soil layer of unknown depth overlying bedrock, with no information on the shear-wave velocity of these layers. Wood et al. (2011) [22] calculated shear wave profiles using the spectral analysis of surface waves (SASW) ground investigation technique for many stations around Christchurch, however their analysis for LPCC was performed approximately 300 metres from the actual station location. Their analysis and interpretation found a soil layer of about 6 metre depth and $V_{\mathrm{S}}$ approximately equal to $300 \mathrm{~m} / \mathrm{s}$ overlying bedrock of $V_{S}=1,520 \mathrm{~m} / \mathrm{s}$, with no other interfaces found down to a depth of 60 metres. The profile determined in the Wood et al. (2011) study is shown below in Figure 5, and corresponds to a $V_{\mathrm{S} 30}$ of $792 \mathrm{~m} / \mathrm{s}$. As the investigation was undertaken far from the actual site, the interface depths may vary spatially, but it is reasonable to assume that the Vs values of the layers are sound and are unchanged within 300 metres.

The average HVSR at LPCC for the 54 selected records is shown in Figure 6a. The $x$ component runs roughly northsouth and the $y$ component roughly east-west. It can be observed in Figure 6a that the HVSR determined using the $x$ component is different from the $y$ component below $10 \mathrm{~Hz}$,

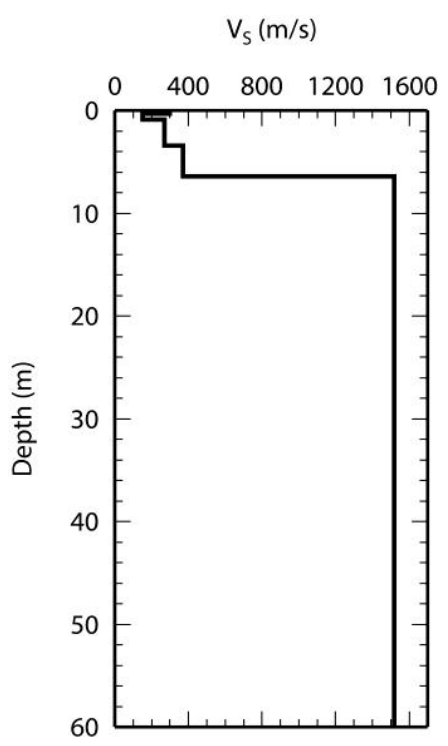

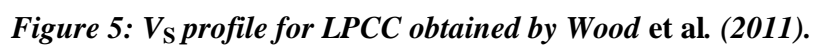

although always within one standard deviation of the mean. As the azimuths of the events used to determine the HVSR were relatively evenly spread around the station, this is unlikely to be a source effect. It is difficult to determine the cause of the difference between the components without a detailed knowledge of the subsurface around the site, but it is possible that this is a $2 \mathrm{D}$ effect related to the steep drop-off of the ground surface on the edge of the port structure to the west of the sensor, acting as an "artificial ridge". If this was the case, we would expect to see higher amplification at a lower natural frequency on the component normal to the slope, which in this case is the $y$ component. This is exactly what is observed in Figure 6a, however detailed investigations would be required to determine whether this is actually the case.

If the profile in Figure 5 is correct, we should see a strong amplification peak at around $12 \mathrm{~Hz}$ on our HVSR, based on the well-known relation

$$
f_{n}=\frac{V_{S}}{4 H}
$$

where $f_{n}$ is the fundamental frequency of the layer in $\mathrm{Hz}, V_{\mathrm{S}}$ is the shear-wave velocity of the soft layer (average velocity approximately $300 \mathrm{~m} / \mathrm{s}$ ) and $H$ is the layer thickness overlying stiff material $(6 \mathrm{~m})$.

Assuming the $x$ component is less influenced by topographic effects, an amplification peak is clearly visible at $7 \mathrm{~Hz}$, which is lower than what would be expected from the Wood et al. (2011) profile. If it is assumed that the known overburden layer has the same $V_{\mathrm{S}}$ as determined by Wood et al. (2011), its depth would correspond to an interface at 11 metres below ground level, by rearranging equation (4).

If the observed amplification is indeed due to a soil overburden layer, it raises the question whether the soil behaved non-linearly during the strongest events from the Canterbury sequence. A subset of 12 events was collected for which the horizontal peak ground acceleration (PGA) was greater than $0.2 \mathrm{~g}$, a threshold above which soil non-linearity can be expected. This was compared to a set of 18 events for which the horizontal PGA was less than $0.05 \mathrm{~g}$, below which there are unlikely to be any non-linear soil effects [23]. If there has been non-linearity (shear modulus degradation) of a soil layer, we would expect a decrease in average shear-wave velocity as per

$$
V_{S}=\sqrt{\frac{G}{\rho}}
$$

where $G$ is the shear modulus and $\rho$ is the mass density, and therefore we should observe a lower fundamental frequency for the large events, as per equation (4) [24, 25].

A reduction in $V_{\mathrm{S}}$ due to soil non-linearity theoretically results in a higher velocity contrast between the soil and the bedrock, but this effect is usually counteracted by an increase in soil damping with shear strain and the overall amplification is reduced, particularly at high frequencies (P.-Y. Bard, pers. comm.).

An HVSR for the subset of large events is compared to that of the smaller event subset in Figure $6 \mathbf{b}$ (only the $y$ component shown for clarity). A shift in fundamental frequency is evident below $8 \mathrm{~Hz}$ that exceeds one standard deviation at 0.7 and 3.5 Hz. However, the amplification does not decrease, as might be expected if the soil had behaved non-linearly, instead it increases to a maximum amplification factor of 4 . While there are a smaller number of events in the average HVSR $>0.2 \mathrm{~g}$ and they are mostly in the near-field, the waves arrive from a variety of azimuths, and thus the difference between the small 
(a)

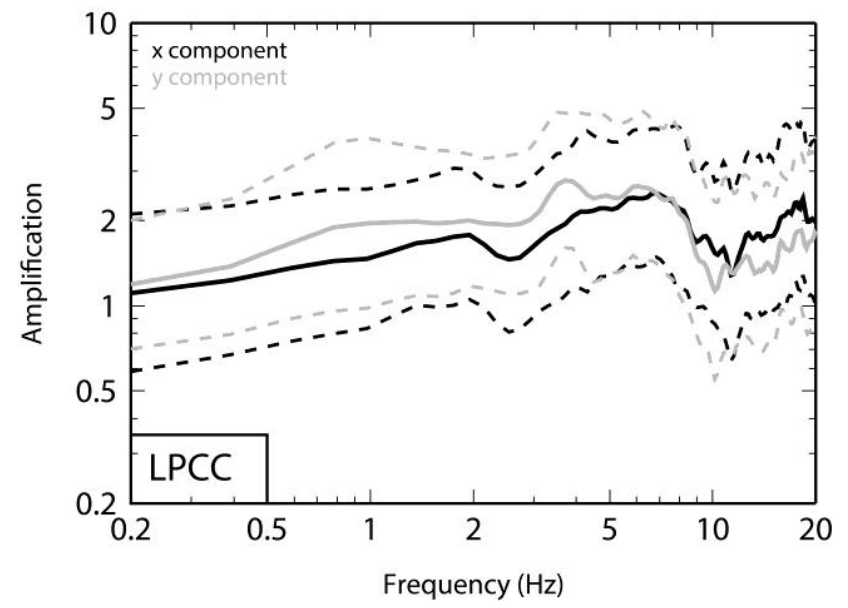

(b)

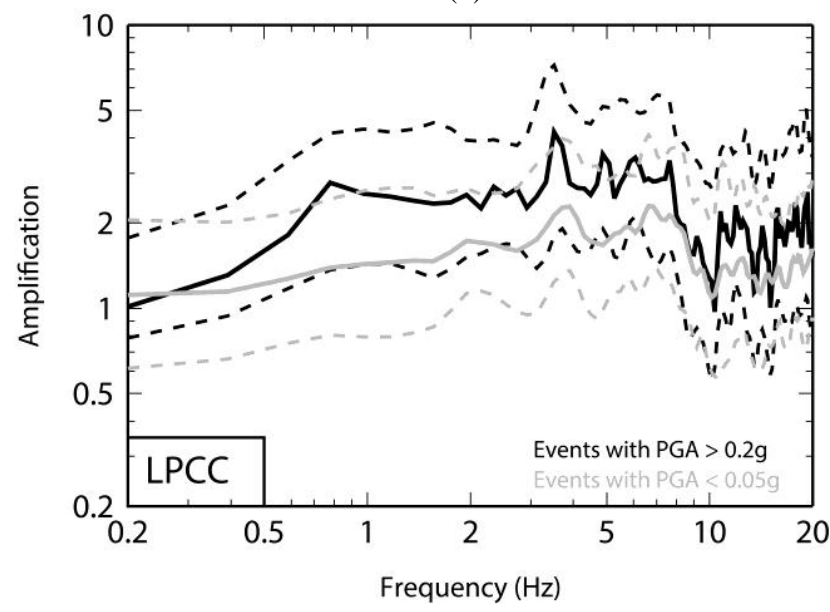

Figure 6: HVSR for LPCC (a) $x$ and y components and (b) for large and small events on the y component. Dashed lines represent $+/$ - one standard deviation from the mean (solid line).

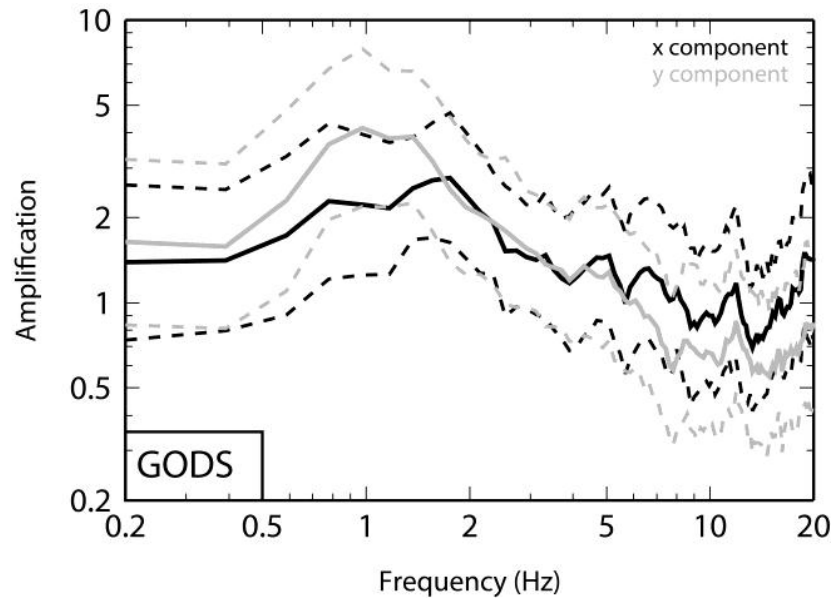

Figure 7: HVSR for GODS x (black, slope parallel) and y (grey, slope normal) components.

and large event HVSRs is unlikely to be a source effect or due to oblique incident waves.

Whether the cause of the difference between large and small events is due to soil non-linearity or otherwise, there are many question marks regarding the actual geological profile beneath LPCC. The station nevertheless does not comply with the Cadet et al. (2010) criteria for a standard rock reference site, as its fundamental frequency is less than $8 \mathrm{~Hz}$.

\section{Godley Drive (GODS)}

The Godley Drive strong motion sensor, located on the crest of a ridge in the Port Hills above Sumner, is a temporary sensor that opened on $26 / 02 / 2011$ and at the time of writing is still operating. From geological maps, the site is located on the same basaltic lava flows as other sites in the Port Hills, therefore is likely to be site class B. No other site information exists for this station. The $x$ component is approximately parallel to the ridge axis and the $y$ component is approximately perpendicular (slope-parallel and slope-normal respectively).

The HVSR shown in Figure 7 is an average for 103 events. The slope-normal component shows greater amplification than the slope-parallel component, with the fundamental frequency around $1 \mathrm{~Hz}$. As such, using GODS as a reference for assessing site effects would result in a large underestimation of amplification at 1 to $2 \mathrm{~Hz}$.

\section{Sign of the Kiwi (D13C / STKS)}

The Sign of the Kiwi strong motion station was originally a temporary sensor installed after the 22 February 2011 Christchurch earthquake (GeoNet code D13C), however it became a permanent station on 13 December 2011 (code STKS). When D13C became STKS, the sensor was relocated 15 metres northeast of the original site and four metres lower. Other than an estimated site classification of B, no geological information is available for this location.

Given that the sensor location changed, HVSRs for the temporary and permanent sensors were compared, shown in Figure 8a. The orientation of the original D13C sensor is unknown, therefore it is not possible to compare one specific component. Instead the geometric mean of the two horizontal components is used to calculate the HVSR. The HVSR curve for D13C is the average of 68 events, while the one for STKS is the average of 55 .

The site response for the two stations appears to be different below $1 \mathrm{~Hz}$, although always within one standard deviation and mostly within a factor of two from unity. The difference between the two curves almost exceeds one standard deviation at $4 \mathrm{~Hz}$, which may be due to sharp spatial variability. Any further conclusions cannot be made without additional site information. Both curves are relatively flat and are similar enough for records to be grouped together. The HVSR curves from both individual components of D13C are compared in Figure 8b. The $x$ component shows a slight peak at $3.5 \mathrm{~Hz}$ 
that may be related to the surface topography (if the orientation is on a slope-normal direction), while the $y$ component is comparably flat. For practical purposes, the $y$ component here can be considered to be an acceptable reference for future site effect studies.

\section{Kennedy Bush Reserve (D14C)}

The Kennedy Bush Reserve is a temporary station installed on $27 / 02 / 2011$. As with the other temporary stations, no

(a)

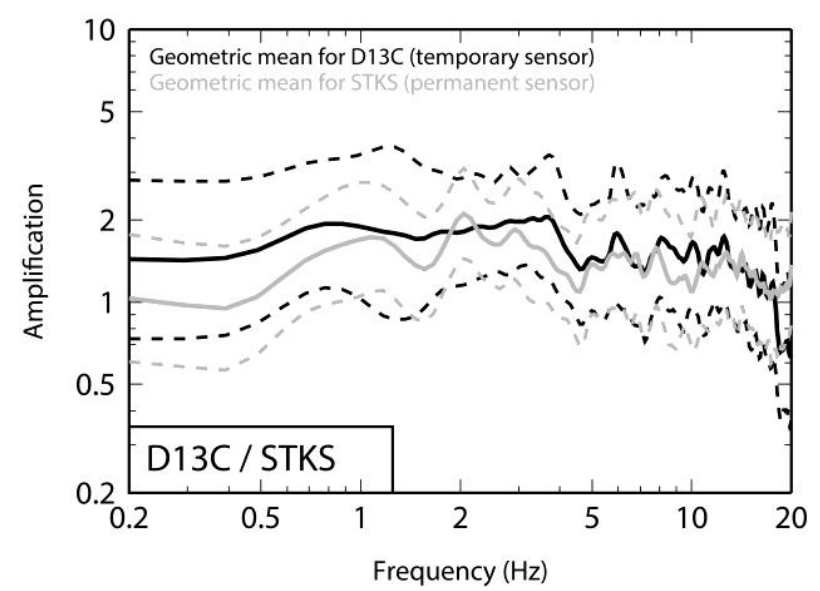

geological information is available other than from geological maps, thus it is assumed that this is located on class B rock in the Port Hills. This is the station with the highest elevation, located 455 metres above sea level near the crest of a ridge. The HVSR in Figure 9 is an average of 104 events, and shows that while there may be slight amplification at $2 \mathrm{~Hz}$, the level of amplification is low and mostly within the accepted uncertainty of the method (i.e. less than 2). There does not appear to be any significant difference between the $x$ and $y$ components and therefore it is a relatively good reference rock site.

(b)

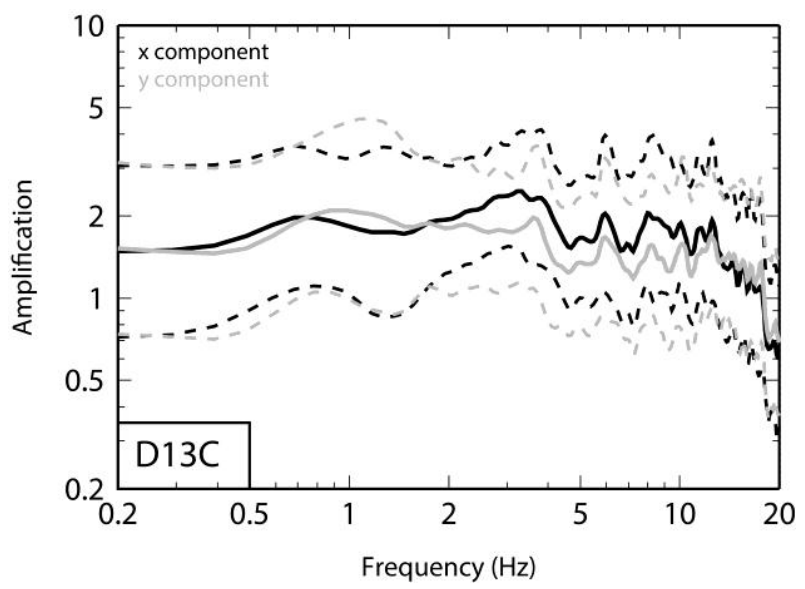

Figure 8: (a) HVSR based on the geometric mean of two horizontal components for D13C (black) and STKS (grey), and (b) HVSR for D13C station for $x$ (black) and y (grey) components.

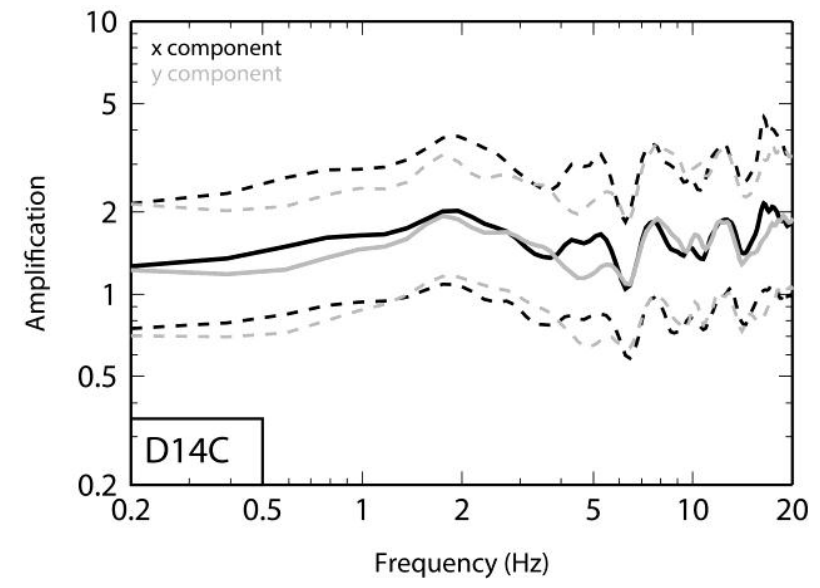

Figure 9: HVSR for D14Cx (black) and y (grey) components.

(a)

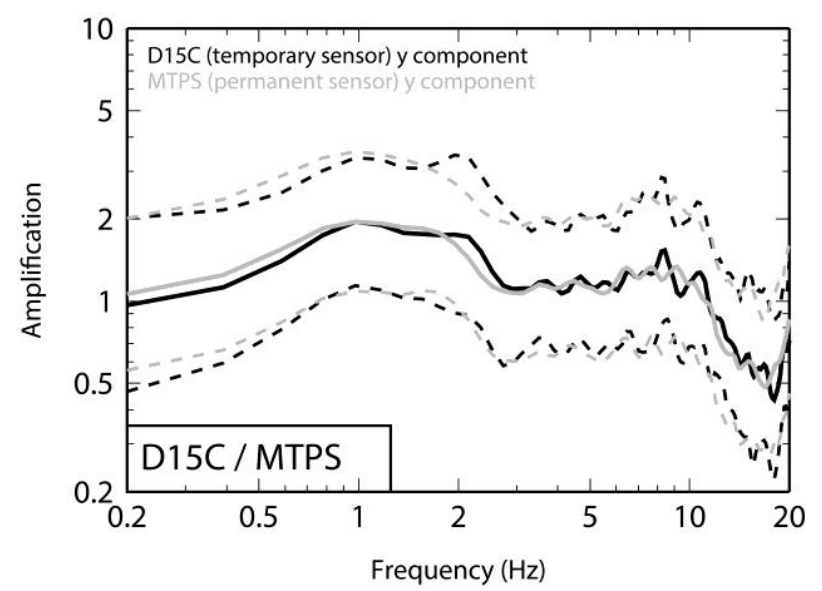

(b)

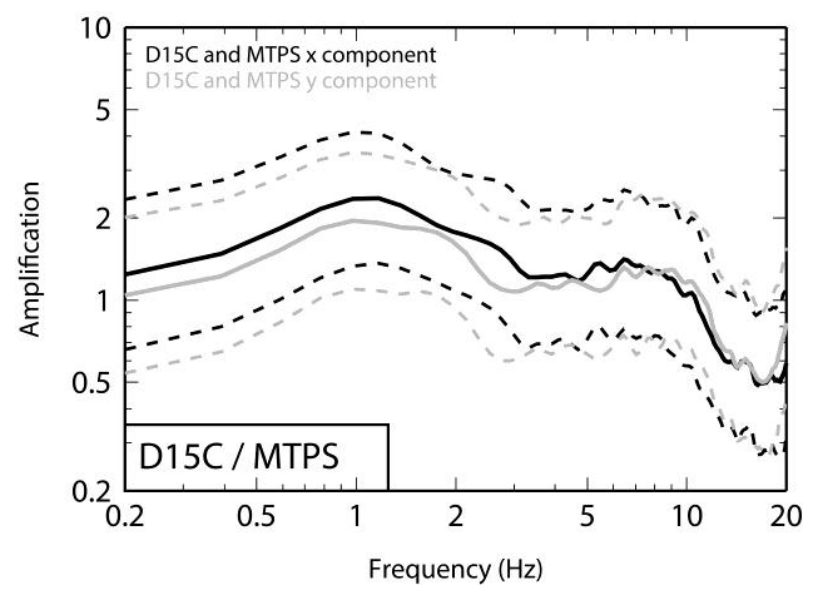

Figure 10: (a) HVSR for 111 D15C events (black) and 23 MTPS events (grey) for the y component only and (b) for all 134 events for both the $x$ (black) and $y$ (grey) components. 


\section{Mount Pleasant Drive (D15C / MTPS)}

Mount Pleasant Drive is a station on the northern side of the Port Hills. It was installed as temporary sensor D15C after the Christchurch earthquake but became permanent station MTPS on 01/03/2012. No $V_{S}$ estimates of the site profile are available. The GeoNet website states that there was no physical change when the station became a permanent one The dataset for this analysis contains 111 events from D15C. At the time of writing, the station had recorded relatively few events as MTPS, as it had only been in operation for seven months. As such, four events from distances greater than $200 \mathrm{~km}$ were included in the HVSR to ensure a reliable average, and a total of 23 events were used.

To verify that there was in fact no physical change when the station was converted from temporary to permanent, HVSRs for the 111 events recorded as D15C were compared to the 23 recorded MTPS, shown in Figure 10a (just the $y$ component is shown for clarity, but the $x$ component is similar). As expected, there is no change between the sensors and it is reasonable to combine data from both the temporary and permanent station. Therefore, Figure 10b shows the HVSR, averaged over all 134 events, for both the $x$ and $y$ components of motion. There appears to be amplification at $1 \mathrm{~Hz}$ at a level slightly greater than 2 . Otherwise, there is little difference between the two components. The amplification at $1 \mathrm{~Hz}$ means that the station does not comply with the Cadet et al. (2010) criteria for standard rock site.

\section{Huntsbury (HUNS)}

The Huntsbury (HUNS) station is the most recently installed sensor analysed here, having started operating on 18/04/2012. The GeoNet site states that this site is located on rock, in a garage set into the hillside. At the time of writing this station had recorded 12 events, nine of which had a SNR of greater than three. As with MTPS, three events of greater epicentral distances (up to $830 \mathrm{~km}$ away, not shown in Figure 2 for practical purposes) were included to obtain a more reliable average. The HVSR for these nine events is shown in Figure 11. The HVSR for just the six events less than $200 \mathrm{~km}$ from the station was also examined and there was no significant difference between the average of six and nine events.

The response of this station is the flattest of all the rock stations, suggesting that it is the best reference site of all the permanent stations analysed in this study. There may be a difference between the two components, however the two curves are always within one standard devation of each other and the amplification factor is less than two. It must however

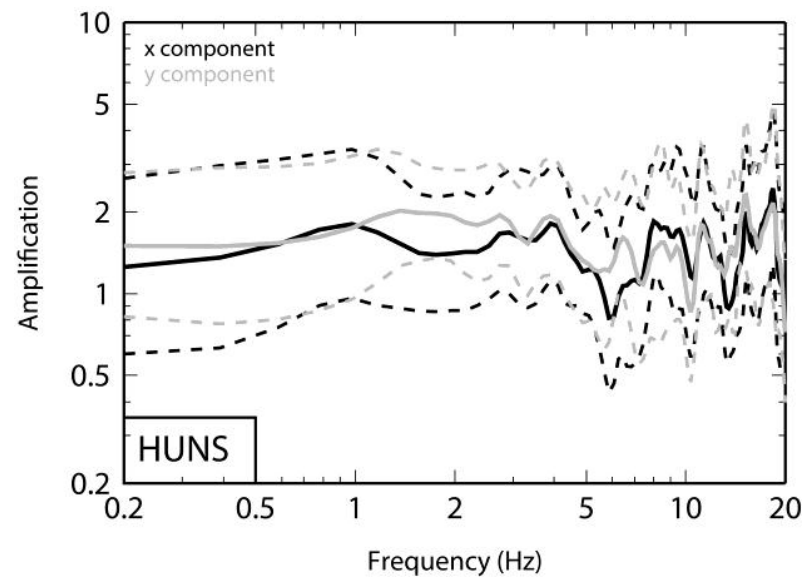

Figure 11: HVSR for HUNS $x$ (black, slope normal) and $y$ (grey, slope parallel) components. be noted that this site has recorded few events thus far, and will need to capture a few more events that are simultaneously recorded on target soil sites before its shape can be verified and its merit as a reference site can be judged.

\section{Heathcote Valley School (HVSC)}

Heathcote Valley School (HVSC) strong motion station is classified as a class $\mathrm{C}$ site by GeoNet and the $V_{\mathrm{S} 30}$ has been previously calculated to be $422 \mathrm{~m} / \mathrm{s}$ by Wood et al. (2011), meaning that the site cannot be a reference site. The non-linear behaviour of the soft soils in Christchurch is well known, however it is interesting to determine whether the stiff soils of the Heathcote Valley also behaved non-linearly during the large events of the Canterbury earthquake sequence. The HVSR method is used here to compare small and large events to look for a shift in natural frequency (as per the method for LPCC detailed earlier).

Figure 12 shows the $V_{\mathrm{S}}$ profile determined by Wood et al. (2011) for the HVSC station. The largest velocity contrast in the profile is approximately two at $17.5 \mathrm{~m}$ depth, above which the time-averaged shear-wave velocity is around $315 \mathrm{~m} / \mathrm{s}$. Applying equation (4) yields an approximate theoretical natural frequency of $4.5 \mathrm{~Hz}$ for this interface. The Wood et al. (2011) study also used HVSR from microtremors and found the fundamental frequency to be $2.4 \mathrm{~Hz}$, which conflicts with their profile determined from the SASW method as it would correspond to a deeper interface. Figure 13a shows the average HVSR for 66 events with SNR > 3, and a welldefined peak is visible at $3.5 \mathrm{~Hz}$ with an amplification factor of 5. The fundamental frequency here, and with the HVSR from microtremors, is lower than what is suggested by the Wood et al. (2011) profile, indicating that either the interface is deeper than they suggest, or the soil above the interface has lower $V_{S}$. Additional site investigation is required to determine which of these is the case.

To assess if the stiff soil at the site behaved non-linearly during the major events, the average HVSRs for 17 events with PGA > 0.2g was compared with 17 events with PGA < $0.05 \mathrm{~g}$. The results are shown in Figure 13b. There is a slight but clear shift in fundamental frequency from 3.8 to $3.1 \mathrm{~Hz}$, with the larger events showing greater amplification at the low frequencies and less amplification above the fundamental frequency up to around $10 \mathrm{~Hz}$, often outside one standard deviation. The shift in the fundamental frequency is an indication that $V_{S}$ of the soil has decreased, and the lower amplification at frequencies higher than $f_{0}$ are likely due to soil damping.

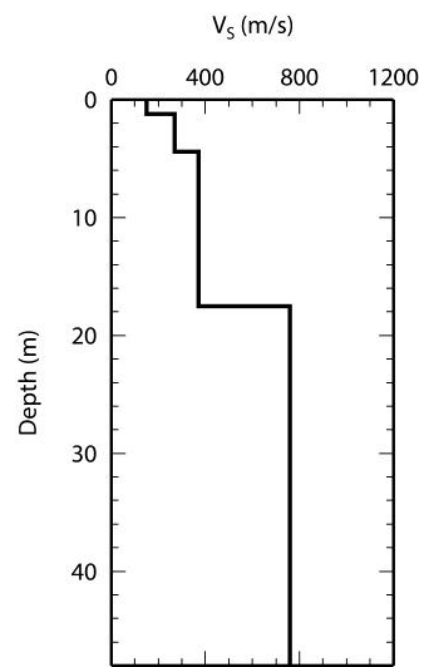

Figure 12: Shear-wave velocity profile for HVSC, from Wood et al. (2011). 
(a)

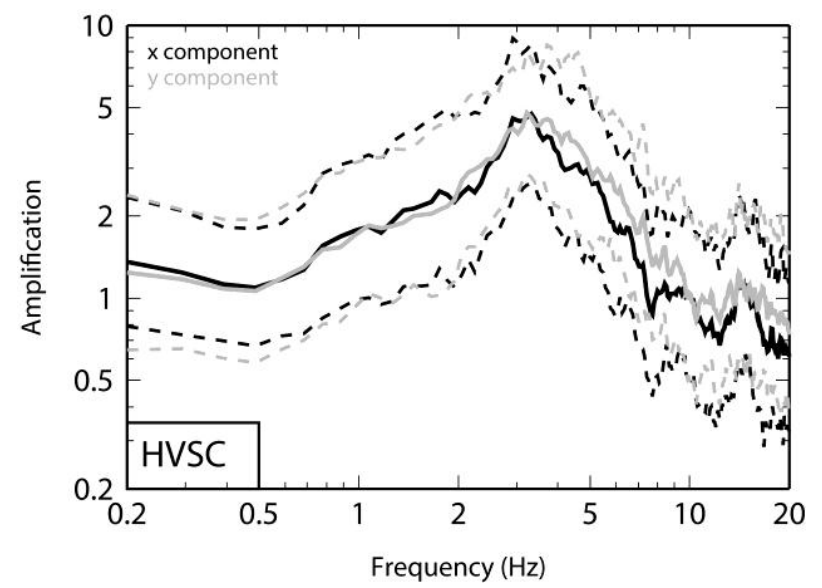

(b)

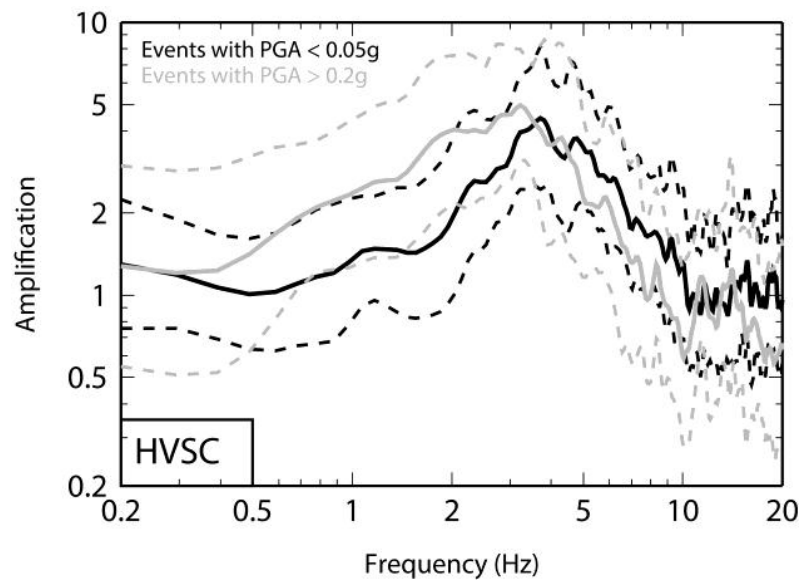

Figure 13: HVSR for HVSC (a) $x$ and y components for all events and (b) for 17 events with PGA $<0.05 g$ and for 17 events with PGA >0.2g. Dashed lines represent +/- one standard deviation from the mean (solid line).

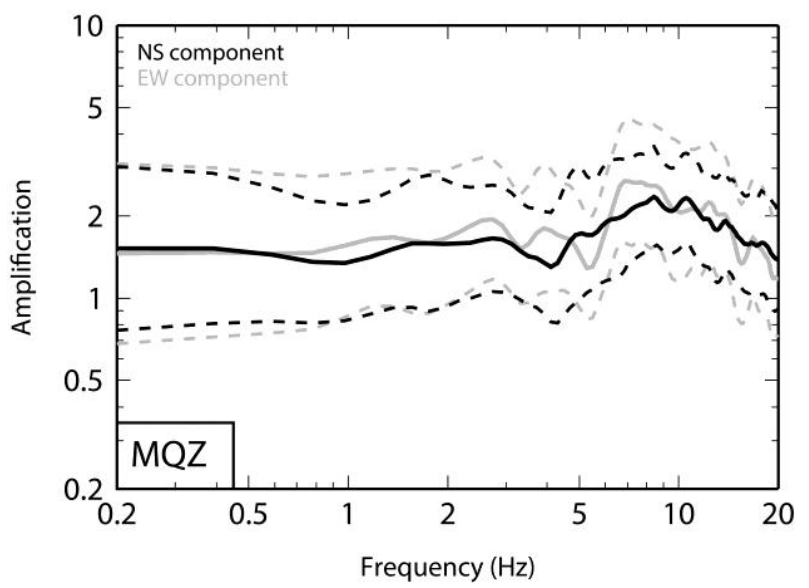

Figure 14: HVSR for MQZ north-south (black)and east-west (grey) components.

\section{McQueen's Valley (MQZ)}

MQZ is located on a broad terrace in moderately steep hill country $20 \mathrm{~km}$ south of the Christchurch CBD. According to GeoNet, the station is located on moderately weathered andesite overlying greywacke and is site class B. The depth of the andesite is in the order of tens to hundreds of metres. As the southernmost station in this study, it is too far from Christchurch to be the best reference site, however it is included here as it is an important rock station in the National Network.

The average HVSR for 230 events recorded by MQZ is shown in Figure 14. While there is a slight difference between the north-south and east-west components, the difference is always within one standard deviation of the mean. An amplification peak can be observed at $7 \mathrm{~Hz}$ on the EW component and at $8.5 \mathrm{~Hz}$ on the NS component. It is possible that the peaks are due to the interface between the andesite and greywacke, but without shear-wave velocity information, conclusions cannot yet be made on the interface depth. The difference between the components may be due to the interface being inclined, or another topographic effect.

Clearly further site information is required to understand the site response of the station. The peak at $7 \mathrm{~Hz}$ means that MQZ cannot be considered a standard rock site.

\section{Oxford (OXZ)}

The OXZ station is located approximately $45 \mathrm{~km}$ from the Christchurch CBD, which rules it out as a reference station for this area. However it is the closest rock site to the west of Christchurch and the nearest rock site to the epicentre of the $M_{\mathrm{w}}$ 7.1 Darfield earthquake of September 2010. The GeoNet website describes this station as located on the end of a very narrow ridge directly on strong greywacke and indicates that there are possible topographic effects at this station.

Figure 15 shows the average HVSR for the OXZ station, calculated from 168 events. There is a clear amplification peak at $1.2 \mathrm{~Hz}$, which is visible on both components. Using HVSR, it is common for an amplification peak caused by an impedance contrast to be accompanied by a trough at approximately 1.73 times the fundamental $S$-wave frequency. This is due to vertical amplification from a $V_{P}$ contrast, and based on an assumed Poisson's ratio of $0.25, V_{P} / V_{S}=1.73$. Here we see a trough here at $2.1 \mathrm{~Hz}$, which is consistent with theory and observations [26]. As the amplification is the same on both horizontal components, it is likely that this amplification is due to a deep interface of weathered material as opposed to topographic effects, as suggested by the GeoNet website. It is possible that there are topographic effects occurring at higher frequencies, however they are not observed by the HVSR method. 


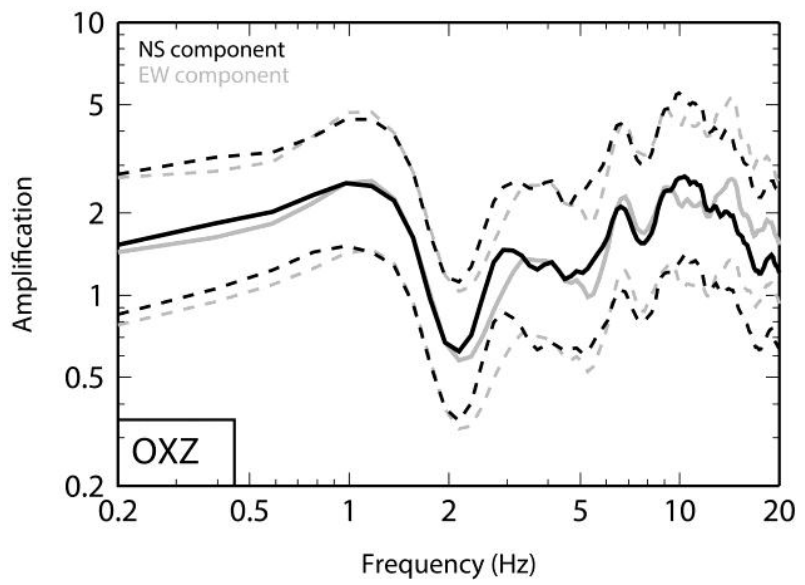

Figure 15: HVSR for OXZ north-south (black)and east-west (grey) components.

\section{SUMMARY}

Table 2 summarises results from the previous section. There are three stations that have a sufficiently flat site response to be considered reference sites, D13C, D14C and HUNS. These sites are located at around 8, 11 and $5 \mathrm{~km}$ from Christchurch CBD respectively. HUNS should therefore be considered the best reference station, as the wave paths for this station and the CBD will be more similar than for the other stations. However, this station has yet to record sufficient common events with other stations in the CBD and will only become useful in the future. As the second closest station with a flat response, the D13C temporary sensor is the best reference station currently available for Christchurch. This station recorded 68 events with epicentral distances less than $200 \mathrm{~km}$ and SNR > 3, and many of these events were simultaneously recorded by several sites around Christchurch. D13C is also the closest station to Lyttelton ( $7 \mathrm{~km}$ away) thus is considered the best reference station for quantifying site effects there.

GeoNet is currently installing a station named Richmond Hill (code SR096) near Sumner that will have two strong motion instruments, one at ground level and one at the bottom of an 80 metre borehole. As the downhole sensor is designed to be at the bedrock, it is possible that this sensor will become the best reference site for Christchurch. Care must be taken with borehole sensors, as destructive interference between upcoming incident waves and down-going surface-reflected waves can affect the response at the borehole sensor and bias surface-to-borehole spectral ratios $[3,27]$. Whether the new

Table 2: Summary of results

\begin{tabular}{cccc}
\hline Station & $\begin{array}{c}\text { Natural } \\
\text { frequency } \\
\text { (Hz) }\end{array}$ & $\begin{array}{c}\text { Peak } \\
\text { amplification } \\
\text { factor }\end{array}$ & $\begin{array}{c}\text { Satisfies } \\
\text { Cadet } \text { et al. } \\
(\mathbf{2 0 1 0}) \\
\text { criteria } \\
\text { (Yes/No) }\end{array}$ \\
\hline CRLZ & 1 & 2.5 & No \\
LPCC & 3.5 & 3.8 & No \\
GODS & 1 & 4 & No \\
D13C / STKS & $-/-$ & $<2 / 2$ & Yes / Yes \\
D14C & - & $<2$ & Yes \\
D15C / MTPS & 1 & 2 & No \\
HUNS & - & $<2$ & Yes \\
HVSC & 3.5 & 5 & No \\
MQZ & 7 & 3 & No \\
OXZ & 1 & 2.5 & No \\
\hline
\end{tabular}

borehole station will be strongly affected by down-going waves depends on the layering above the site, and knowledge of the $V_{S}$ profile between the paired sensors is essential before the borehole station can be used as a reference.

\section{CONCLUSIONS}

With several site effect investigations being undertaken for the Christchurch CBD, this study analyses the rock stations nearest to Christchurch to determine what the site effects should be measured relative to. Using horizontal-to-vertical spectral ratios for earthquake records, a non-reference method, site effects are investigated at nine stations around Christchurch that are classified as rock, and one that is classified as stiff soil.

The LPCC station is commonly used as the reference rock site in several site effect studies. However, the HVSRs show that there is site amplification at $7 \mathrm{~Hz}$, likely due to the known soil overburden layer at the site. It is possible that this layer behaved non-linearly during the largest events from the Canterbury earthquake sequence, however this is still unclear and requires further investigation. Observed amplification on the $y$ component at $4 \mathrm{~Hz}$ is likely to be due to topographic effects from a nearby "artificial ridge" created by the inside edge of the port structure. Two other stations, CRLZ and GODS, appear to have topographic amplification effects. Three temporary sensors placed in the Port Hills after the 22 February 2011 Christchurch earthquake show slight amplification in the 1 to $2 \mathrm{~Hz}$ band, but otherwise appear to have a relatively flat response. While there may be a slight difference between the site responses at the D13C/STKS stations due to the relocation of the sensor in December 2011, the difference is small and the records from both stations can be grouped together.

The newest station analysed here, HUNS, is considered the best reference station as is the closest to Christchurch with a flat site response, however this needs to be verified when more events are available. The D13C temporary station is currently the best available reference station for both Christchurch and Lyttelton.

MQZ has an amplification peak at $7 \mathrm{~Hz}$, which may be due to an andesite-greywacke rock interface. The OXZ station, located around $45 \mathrm{~km}$ from Christchurch, is classified as a rock site, but appears to have amplification effects due to an impedance contrast. Any high-frequency topographic amplification, which is suggested by the GeoNet website, may not be captured using this method. The HVSC stiff soil station shows strong amplification at its fundamental frequency of 3.5 $\mathrm{Hz}$, and the HVSR method has been used to demonstrate that 
the soil beneath the station is likely to have behaved nonlinearly in the largest events from the earthquake sequence.

\section{ACKNOWLEDGMENTS}

The authors wish to acknowledge Pierre-Yves Bard from ISTerre in Grenoble, France, for his useful opinions on interpretation of HVSRs, and Caroline Holden for her thoughtful review and comments. The second author would like to thank cats for providing inspiration and motivation. Signal processing greatly benefitted from the use of Seismic Analysis Code (SAC2008, http://www.iris.edu/software/sac) [28, 29]. Figures were created using Generic Mapping Tools [30]. We also acknowledge the New Zealand GeoNet project and its sponsors EQC, GNS Science and LINZ, for providing the data used in this study.

\section{REFERENCES}

1. GNS Science, (2012). "GeoNet" (last accessed 29 October 2012). Available from: www.geonet.org.nz.

2. Borcherdt, R.D., (1970). "Effects of local geology on ground motion near San Francisco Bay". Bulletin of the Seismological Society of America, 60(1): 29-61.

3. Steidl, J.H., A.G. Tumarkin and A.J. Archuleta, (1996). "What is a reference site?". Bulletin of the Seismological Society of America, 86(6): 1733-1748.

4. Boore, D.M. and W.B. Joyner, (1997). "Site amplifications for generic rock sites". Bulletin of the Seismological Society of America, 87(2): 327-341.

5. Tucker, B.E., J.L. King, D. Hatzfeld and I.L. Nersesov, (1984)."Observations of hard-rock site effects". Bulletin of the Seismological Society of America, 74(1): 121136.

6. Cadet, H., P.-Y. Bard and A. Rodriguez-Marek, (2010). "Defining a Standard Rock Site: Propositions Based on the KiK-net Database". Bulletin of the Seismological Society of America, 100(1): 172-195.

7. Smyrou, E., P. Tasiopoulou, I.E. Bal and G. Gazetas, (2011). "Ground motions versus geotechnical and structural damage in the February 2011 Christchurch earthquake". Seismological Research Letters, 82(6): 882-892.

8. Guidotti, R., M. Stupazzini, C. Smerzini, R. Paolucci and P. Ramieri, (2011). "Numerical study on the role of basin geometry and kinematic seismic source in $3 \mathrm{~d}$ ground motion simulation of the 22 February $2011 \mathrm{MW}$ 6.2 Christchurch earthquake". Seismological Research Letters, 82(6): 767-782.

9. Bradley, B.A. and M. Cubrinovski, (2011). "Near-source strong ground motions observed in the 22 February 2011 Christchurch earthquake". Bulletin of the New Zealand Society for Earthquake Engineering, 44(4): 181-194.

10. Kaiser, A.E., R.A. Benites, A.I. Chung, A.J. Haines, E. Cochran and B.I. Fry, (2011). "Estimating seismic site response in Christchurch city (New Zealand) from dense low-cost aftershock arrays". in 4th IASPEI / IAEE International Synopsium. 2011. University of California Santa Barbara.
11. Taber, J.J. and H.A. Cowan, (1993). "Measurement of earthquake ground shaking at characteristic sites in Christchurch". A Report Prepared for The Earthquake Commission and Canterbury Regional Council, Christchurch.

12. Toshinawa, T., J.J. Taber and J.B. Berrill, (1997). "Distribution of ground-motion intensity inferred from questionnaire survey, earthquake recordings, and microtremor measurements - A case study in Christchurch, New Zealand, during the 1994 Arthurs Pass Earthquake". Bulletin of the Seismological Society of America, 87(2): 356-369.

13. Nakamura, Y., (1989). "Method for dynamic characteristics estimation of subsurface using microtremor on the ground surface". Quarterly Report of RTRI (Railway Technical Research Institute) (Japan), 30(1): 25-33.

14. Lermo, J. and F.J. Chavez-Garcia, (1993). "Site effect evaluation using spectral ratios with only one station". Bulletin of the Seismological Society of America, 83(5): 1574-1594.

15. Parolai, S. and S.M. Richwalski, (2004). "The importance of converted waves in comparing $\mathrm{H} / \mathrm{V}$ and RSM site response estimates". Bulletin of the Seismological Society of America, 94(1): 304-313.

16. Chávez-García, F.J., L.R. Sánchez and D. Hatzfeld, (1996). "Topographic site effects and HVSR. A comparison between observations and theory". Bulletin of the Seismological Society of America, 86(5): 15591573.

17. Ktenidou, O.-J., F.J. Chávez-García and K.D. Pitilakis, (2011). "Variance Reduction and Signal-to-Noise Ratio: Reducing Uncertainty in Spectral Ratios". Bulletin of the Seismological Society of America, 101(2): 619-634.

18. Bonilla, L.F., J.H. Steidl, J.-C. Gariel and R.J. Archuleta, (2002). "Borehole Response Studies at the Garner Valley Downhole Array, Southern California". Bulletin of the Seismological Society of America, 92(8): 3165-3179.

19. Standards New Zealand, (2004). "NZS1170.5 Earthquake actions - New Zealand". Wellington, New Zealand.

20. Forsyth, P.J., D.J.A. Barrell and R. Jongens, (2008). "Geology of the Christchurch area: scale 1:250,000": Institute of Geological \& Nuclear Sciences 1:250,000 geological map 19.64 p. +1 folded map

21. "Ring Laser Project webpage" (last accessed 12 November 2012). Available from: http://www.ringlaser.org.nz/content/cashmere_cavern_la boratory.php.

22. Wood, C.M., B.R. Cox, L.M. Wotherspoon and R.A. Green, (2011). "Dynamic site characterization of Christchurch strong motion stations". Bulletin of the New Zealand Society for Earthquake Engineering, 44(4): 195-204

23. King, J.L. and B.E. Tucker, (1984). "Observed variations of earthquake motion across a sediment-filled valley". Bulletin of the Seismological Society of America, 74(1): 137-151.

24. Dimitriu, P., N. Theodulidis and P.Y. Bard, (2000). "Evidence of nonlinear site response in HVSR from SMART1 (Taiwan) data". Soil Dynamics and Earthquake Engineering, 20(1-4): 155-165. 
25. Wen, K., T. Chang, C. Lin and H. Chiang, (2006). "Identification of nonlinear site response using the H/V spectral ratio method". Terrestrial Atmospheric and Oceanic Sciences, 17(3): 533.

26. Konno, K. and T. Ohmachi, (1998). "Ground-motion characteristics estimated from spectral ratio between horizontal and vertical components of microtremor". Bulletin of the Seismological Society of America, 88(1): 228-241.

27. Assimaki, D., W. Li, J.H. Steidl and K. Tsuda, (2008). "Site amplification and attenuation via downhole array seismogram inversion: A comparative study of the 2003 Miyagi-Oki aftershock sequence". Bulletin of the Seismological Society of America, 98(1): 301-330.

28. Goldstein, P., D. Dodge, M. Firpo and L. Minner, (2003). "SAC2000: Signal processing and analysis tools for seismologists and engineers", in The IASPEI International Handbook of Earthquake and Engineering Seismology, W.H.K. Lee, H. Kanamori, P.C. Jennings, and C. Kisslinger (Editors), Academic Press London.

29. Goldstein, P. and A. Snoke, (2005). "SAC availability for the IRIS community". DMS Electronic Newsletter, $7(1)$.

30. Wessel, P. and W.H.F. Smith, (1998). "New and improved version of the Generic Mapping Tools released". EOS Trans. AGU, 79: 579. 